\title{
IEA/SHC
}

Task 57, Subtask B

Draft proposals for new test procedures

B2: Final Draft

\section{Draft proposals for Test methods for mechanical load on the support of close-coupled solar water heating systems}

Shen Bin

Zhejiang Provincial Solar Energy Products Quality Inspection and

Testing Center (STCCZJ), China

28 September 2018 


\section{Contents}

1 Scope

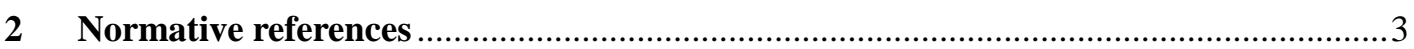

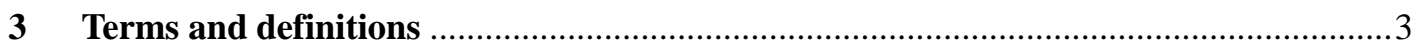

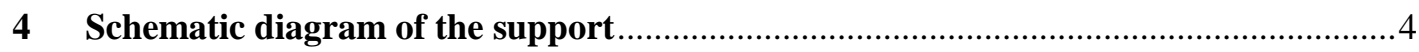

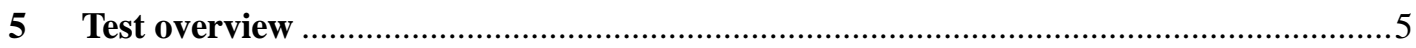

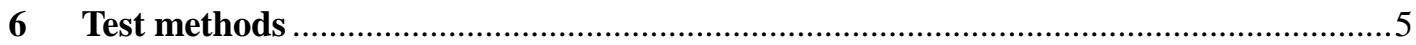

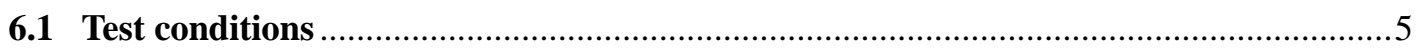

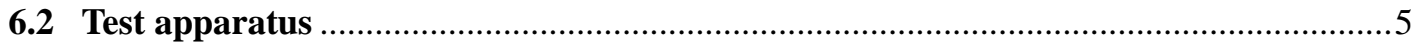

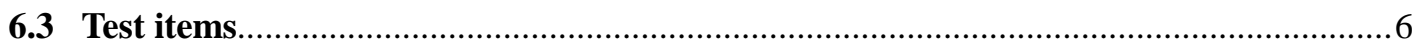

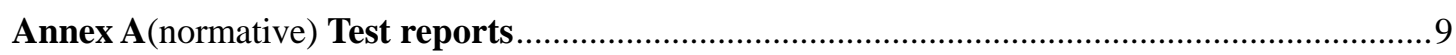

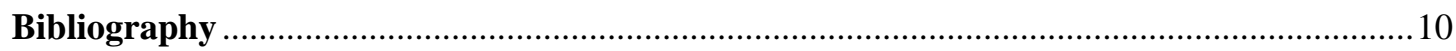




\section{Test methods for mechanical load on the support of close-coupled solar water heating systems}

\section{Scope}

This standard stipulates the classification, technical requirements, test methods, inspection rules, labeling, packaging, transportation and store.

This standard is appropriate to the support of close-coupled type domestic solar water heating system(the tank storage capacity less than $0.6 \mathrm{~m}^{3}$ ) and the supports of which are made from galvanized iron sheet or aluminium alloy or/and stainlesssteel. The supports are processed by panel beating, surface paint-spraying and surface plastic-spraying. The testing method of the supports made from other materials or other processing of surface treatments can refer to this standard.

\section{Normative references}

The following documents, in whole or in part, are normatively referenced in this document and are indispensable for its application. For dated references, only the edition cited applies. For undated references, the latest edition of the referenced document (including any amendments) applies.

ISO $9488 \quad$ Solar Energy - Vocabulary

EN 1991-1-3 Specification 1 -Structural Behavior, Part 1 - 3: General-Snow Load

EN 1991-1 - $4 \quad$ Specification 1-Structural Behavior, Part 1 - 4: General - Wind Load

EN 12976-2 Thermal solar systems and components - Factory made systems Part 2: Test methods;

\section{Terms and definitions}

For the purpose of this standard, the terms and definitions given in ISO 9488 apply, together with the following additional terms and definitions:

\section{1 support of close-coupled solar water heating system}

For supporting, fixing heat storage tank and other parts of solar water heating system. The support which has a certain angle

\section{2 tank bracket}

bracket for supporting, fixing heat storage tank

\section{3 strength}

ability of the support to bear the snow load 


\section{4 stiffness}

anti-deformation ability of the support to withstand the simulated wind load

\section{5 stability}

front leg, back leg and fastener of the support to withstand the simulated wind load

\section{Schematic diagram of the support}

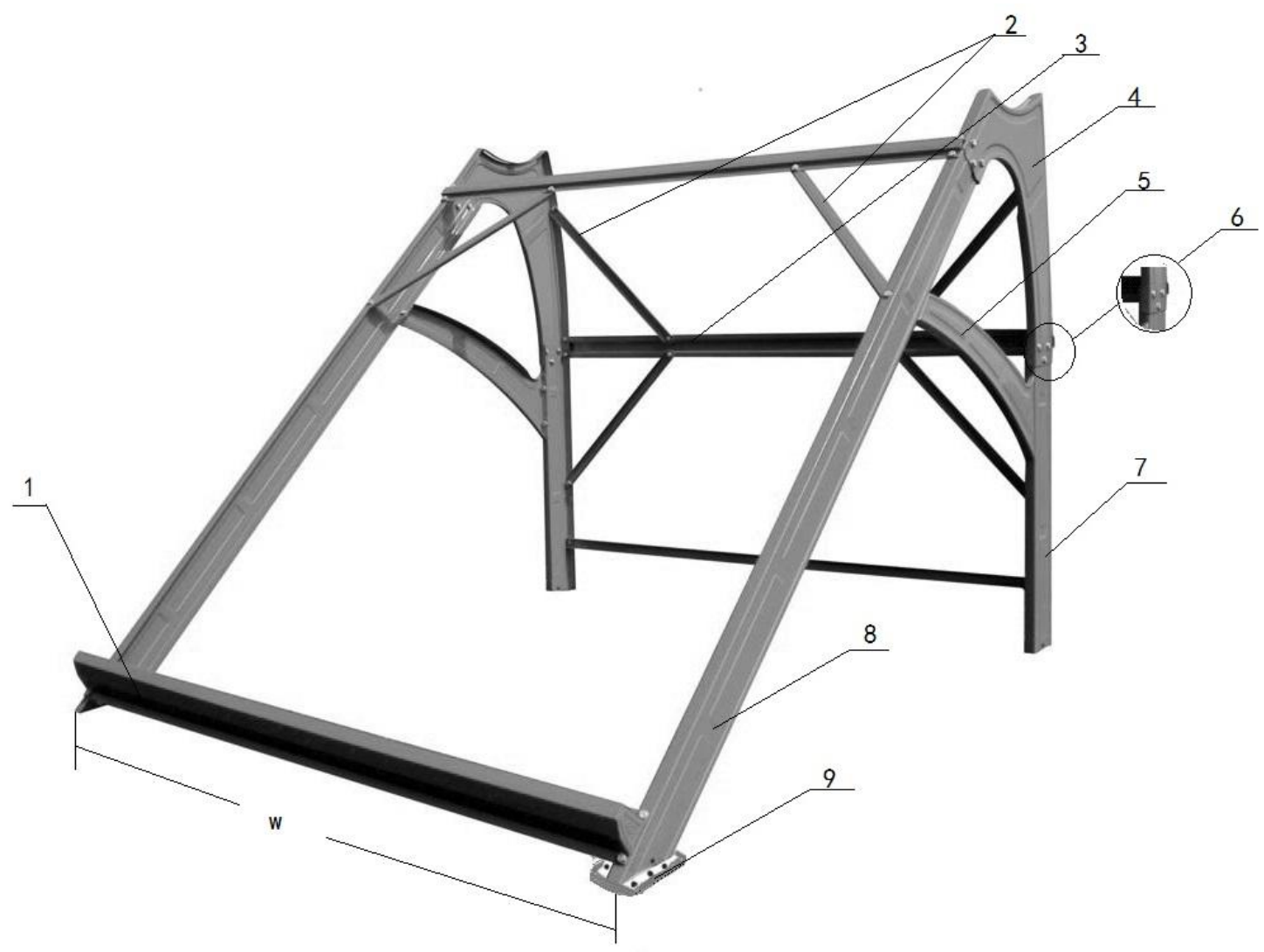

Introductions:

1 - tail box

$2 \_$diagonal pull rod

3 - transcripts

4 - bucket care

5 - fastener

6-bracing

7 - rear leg

8 - front leg

9 - ottomans

Figure 1 - Schematic diagram of the support 


\section{Test overview}

The test of the mechanical load on the support of a close-coupled solar water heating system can be divided into three aspects: strength (static), stiffness (dynamic), stability (dynamic). The specific test methods are described in Chapter 6 and test items are shown in Table 1.

Table 1 - Test items

\begin{tabular}{|l|l|}
\hline Clause & Test \\
\hline 6.3 .1 & Strength (static) \\
\hline 6.3 .2 & Stiffness (dynamic) \\
\hline 6.3 .3 & Stability (dynamic) \\
\hline
\end{tabular}

\section{Test methods}

\subsection{Test conditions}

The indoor temperature of the test room should be kept within the range of $8{ }^{\circ} \mathrm{C}$ to $35^{\circ} \mathrm{C}$ with no requirement for the indoor humidity.

\subsection{Test apparatus}

The test apparatus is shown in Figure 2.

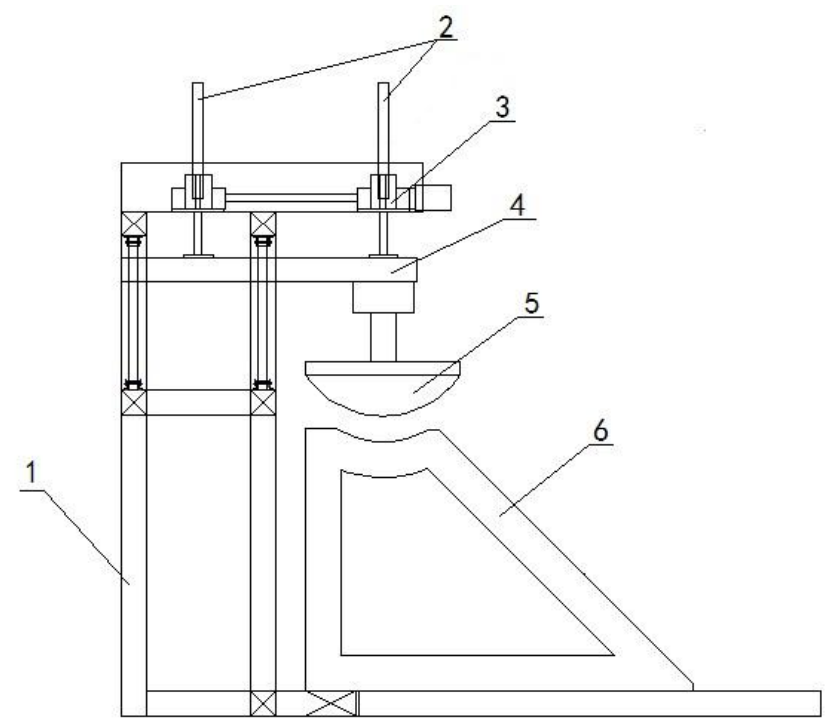

Figure 2 - Schematic diagram of support structure performance test bench

Introductions:

1 - test apparatus

2 - support drive lead screw

3 - displacement driving device (forward, backward, left, right four directions)

4 _ test fixture (include sensor)

$5-$ simulated water tank

6 - tested support 


\subsection{Test items}

\subsubsection{Strength test (static)}

\subsubsection{Objective}

Test the static load capacity.

\subsubsection{Test procedure}

a) Firstly, the support of solar water heating system is installed and fixed according the installation instructions.

b) The support structural performance test apparatus is connected to the power and turned on. The test apparatus 1 is lifted.

c) And then, the solar water heating system support is lifted horizontally and placed on the support structural performance test apparatus. The four corners of the support are fixed.

d) The simulated water tank 5 is mounted on the test fixture 4 . The test apparatus is putted down gradually and the displacement driving device 3 is adjusted forward or backward. At this time, the convex surface of the simulated water tank 5 is in perfect conformity with the concave of the solar water heater bracket. Moreover, the displacement driving device 3 is adjusted lift or right. The left and right sides of the simulated water tank 5 are equal to the sides of the solar water heating system support. To ensure that the support is evenly loaded.

e) Screwing down the support drive lead screw 2 step by step to apply pressure evenly to the solar water heating system support. When the power is 1.5 times to the capacity of the rated heat storage tank, the support drive lead screw 2 stop. The applied load must be held for 15 minutes. (Such as in the course of the test stent obvious deformation or collapse should immediately stop testing and unload the load).

f) After 15 minutes, gradually adjusting the support drive lead screw 2 upwards and the applied load on the solar water heating system support is removed step by step.

g) After the experiment, the integrity of the solar water heating system support is inspected.

\subsubsection{Test results}

Check the support damage and deformation and record, support if collapsed or greater than $1 \mathrm{~cm}$ deformation that is not passed the test.

\subsubsection{Stiffness test (Dynamic)}

\subsubsection{Objective}

The stability of the support in the dynamic case (simulated outdoor wind).

\subsubsection{Test procedure}

a) Firstly, the support of solar water heating system is installed and fixed according the installation instructions.

b) The support structural performance test apparatus is connected to the power and turned on. The test apparatus 1 is lifted.

c) And then, the solar water heating system support is lifted horizontally and placed on the support structural performance test apparatus. The four corners of the support are fixed.

d) The simulated water tank 5 is mounted on the test fixture 4 . The test apparatus is putted down 
gradually and the displacement driving device 3 is adjusted forward or backward. At this time, the convex surface of the simulated water tank 5 is in perfect conformity with the concave of the solar water heating system supports. Moreover, the displacement driving device 3 is adjusted lift or right. The left and right sides of the simulated water tank 5 are equal to the sides of the solar water heating system support. To ensure that the support is evenly loaded.

e) Screwing down the support drive lead screw 2 step by step to apply pressure evenly to the solar water heating system support. When the power is 1.5 times to the capacity of the rated heat storage tank, the support drive lead screw 2 stop. At this time, the displacement driving device 3 starts to move right and left periodically to drive the solar water heating system support swing left and right. The sway force of the displacement driving device 3 is $300 \mathrm{~N}$ and the left and right swings frequency of the displacement driving device 3 is 30 times per minute.

f) The stiffness test for the support of the solar water heating system last for 10 minutes. (Such as in the course of the test stent obvious deformation or collapse should immediately stop testing and unload the load).

g) After 10 minutes, gradually adjusting the support drive lead screw 2 upwards and the applied load on the solar water heating system support is removed step by step.

h) After the experiment, the integrity of the solar water heating system support is inspected.

\subsubsection{Test results}

After the test, check the support damage and deformation.

\subsubsection{Stability test(Dynamic)}

\subsubsection{Objective}

The stability of the support in the dynamic case (simulated outdoor wind).

\subsubsection{Test procedure}

a) Firstly, the support bracket of solar water heating system is installed and fixed according the installation instructions.

b) The support structural performance test apparatus is connected to the power and turned on. The test apparatus 1 is lifted.

c) And then, the solar water heating system support is lifted horizontally and placed on the support structural performance test apparatus. The four corners of the support are fixed.

d) The simulated water tank 5 is mounted on the test fixture 4. The test apparatus is putted down gradually and the displacement driving device 3 is adjusted forward or backward. At this time, the convex surface of the simulated water tank 5 is in perfect conformity with the concave of the solar water heating system support. Moreover, the displacement driving device 3 is adjusted lift or right. The left and right sides of the simulated water tank 5 are equal to the sides of the solar water heater bracket. To ensure that the support is evenly loaded.

e) Screwing down the support drive lead screw 2 step by step to apply pressure evenly to the solar water heating system support. When the power is 1.5 times to the capacity of the rated heat storage tank, the support drive lead screw 2 stop. At this time, the displacement driving device 3 starts to move forward and backward one time to drive the support swing left and right. The sway force of the displacement driving device 3 is $500 \mathrm{~N}$.

f) The stability test on the support of the solar water heating system is conducted only once. 
(Such as in the course of the test stent obvious deformation or collapse should immediately stop testing and unload the load).

g) After the stability test, gradually adjusting the support drive lead screw 2 upwards and the applied load on the support is removed step by step.

h) Finally, the integrity of the solar water heating system support is inspected.

\subsubsection{Test results}

Check the stability of the support, and support deformation and so on should not appear before and after the legs out of the ground. 


\section{Annex A}

\section{(normative)}

\section{Test reports}

Test reports shall be issued in accordance to the International Standard ISO/IEC 17025.

\section{A.1 General}

System reference No:

Test performed by:

Address:

Date, Telephone, Fax:

\section{A.2 Description of the solar water heating system}

Name of manufacturer:

Name of brand:

Serial No:

Drawing document No:

Year of production:

Configuration scheme of the system:

\section{A.3 Test results record}

\begin{tabular}{|l|l|l|l|}
\hline \multicolumn{1}{|c|}{ Test } & \multicolumn{1}{|c|}{ Testing requirements } & Description of the results & Other \\
\hline Strength & Test weight: Kg, Time: min & & \\
\hline Stiffness & $\begin{array}{l}\text { Test force: } 300 \mathrm{~N}, \text { frequency: times/min, Time: } \\
\text { min }\end{array}$ & & \\
\hline Stability & Test force: $500 \mathrm{~N}$, frequency: times & & \\
\hline
\end{tabular}




\section{Bibliography}

[1] Chinese National Standard, GB/T 19141-2011, Specifications of domestic solar water heating systems.

[2] Chinese Industry Standard, NB/T 34022-2016, Support of domestic solar water heaters 